\title{
Atypical autism
}

INSERM

\section{Source}

INSERM. (1999). Orphanet: an online rare disease and orphan drug data base. Atypical autism. ORPHA:199627

Atypical autism is a pervasive developmental disorder that does not fit the diagnosis for the other specific autistic spectrum disorders (autism, Asperger syndrome, Rett syndrome or childhood disintegrative disorder; see these terms) and is characterized by usually milder developmental and social delay and less stereotypical autistic behavior. ' 